RESEARCH ARTICLE

\title{
Cardiovascular Risk in Patients with Chronic Kidney Disease is Associated with Decrease of HDL Levels
}

Cícera Jacqueline da Conceição Silva ${ }^{1}$, Rafaely Pereira de Alencar ${ }^{1}$, Leticia Miranda Tenório ${ }^{1}, \mathrm{Na-}$ thanielly Lima da Silva ${ }^{1}$, Amanda Feitosa de Barros ${ }^{1}$, Chiara Rachel Maciel Marinho ${ }^{1}$ and Raphael de Souza Pinto ${ }^{1,2 *}$

${ }^{1}$ Cesmac University Center, Brazil

${ }^{2}$ Lipids Laboratory of Medical Faculty, University of São Paulo, Brazil

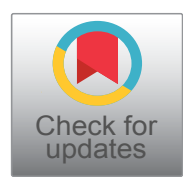

*Corresponding author: Raphael de Souza Pinto, PhD, Lipids Laboratory of Medical Faculty, University of São Paulo; Cesmac University Center, Brazil, E-mail: rspinto@usp.br

\begin{abstract}
Background: Cardiovascular diseases are the leading causes of death in patients with Chronic Kidney Disease (CKD) and several factors are associated with atherosclerosis in this pathology.

Objective: We evaluate the metabolic profile from risk factors associated with the development of atherosclerosis in patients with CKD.

Method: Biological markers for renal function and associated with atherosclerosis were analyzed from serum samples of 23 patients before undergoing hemodialysis procedure.
\end{abstract}

Results: We observed a correlation of HDL with creatinine. Moreover, a positive correlation was observed between serum albumin levels and the values of VLDL and triglycerides, concomitant with a decrease in HDL.

Conclusion: The loss of renal function decreases HDL levels contributing to the development of atherosclerosis in these patients.

\section{Keywords}

Chronic kidney disease, Atherosclerosis, HDL

\section{Introduction}

Cardiovascular diseases are the leading causes of death in patients undergoing hemodialysis. Despite new treatments and advances in dialysis processes, patients with chronic kidney disease (CKD) have 10 to 20 times higher mortality rate from cardiovascular disease compared to geral population $[1,2]$.
Several factors associated with atherosclerosis are found in patients with CKD, with high prevalence hypertension, dyslipidemia, diabetes mellitus and smoking, considering these risk factors associated with more traditional atherosclerosis in DRC [3,4]. Moreover, they are also described other non-traditional factors associated with atherosclerosis in these patients, for example, infections, proteinuria, hyperphosphatemia, and oxidative stress [4].

Increased oxidative stress in patients with CKD may be due to increased serum levels of urea, already has shown an increase of lipid peroxidation and protein in animal models and in humans with high levels of uréia [5-7]. Furthermore, cell incubation with urea increases stress oxidative $[8,9]$. Into animal models of chronic kidney disease was observed that increased oxidative stress causes insulin resistance and glucose intolerance by modifying signaling insulin pathway [9].

Dyslipidemia can lead to the development of atherosclerosis due to high plasma concentration of low density lipoproteins (LDL) and decreased high-density lipoprotein (HDL), one of the most important risk factors in evidence indicate that aterosclerose [10-12]. Besides, the moderate increase in triglycerides leads to formation of new atherosclerotic lesions [12]. The onset of dyslipidemia is sometimes very early and varies in relation to the performance of renal function and drug and dialysis therapies. In addition, changes in the lipid pro- 
file aggravate the progression of the disease renal [13].

Together, these events favor the establishment of a pro-atherogenic profile, considering the involvement of triglyceride-rich lipoproteins - chylomicrons (CM), very low-density lipoproteins (VLDL) and their remnants - and smaller LDL in genesis of atherosclerotic injury [14-18].

The objective of this study was to evaluate the metabolic profile of risk factors associated with the development of atherosclerosis of patients undergoing hemodialysis process.

\section{Material and Methods}

The survey was conducted in two institutions, the Cesmac University Center and a hospital in the city of Maceió, Brazil. Patients on hemodialysis at the Nephrology department of this hospital were invited to participate in this survey, being informed of the dosages that were carried out with samples assigned in just before the hemodialysis process and received information about the preparation of patients for obtaining samples such as fasting time, habitual diet and weight maintained for at least two weeks and no vigorous physical activity during the 24 hours preceding the examination. In addition to avoiding the use of alcohol in the 72 hours prior. The serial measurements were performed in the same laboratory to minimize the effect of the analytical variation. They were informed patients all the research procedures and guaranteed the confidentiality of the data.

\section{Ethical aspects}

The study was submitted and approved by the Research Ethics Committee (COEPE) of Cesmac University Center, under protocol number 1502/12.

\section{Biochemical}

The samples were collected by vein puncture without anticoagulant in biochemistry tube. Subsequently the material is centrifuged for about 10 minutes to apply the technique to the dosages semi-automated equipment Bio $200 \mathrm{~F}$ (Bioplus) following the guidelines of the starter Labtest Diagnostics S/A.

Fasting blood glucose was measured by glucose oxidase method, total cholesterol, triglycerides, HDL and urea by colorimetric enzyme reactions. The amounts of low density lipoprotein (LDL) were achieved by Friedewald [19] for calculating triglycerides below $400 \mathrm{mg} / \mathrm{d}$. Albumin by colorimetric bromocresol green method. Creatinine was obtained by the kinetic two-point method.

The C-reactive protein was determined by agglutination method following the manufacturer's instructions. For internal quality control, we used a control serum of the same brand of reagents.

\section{Statistical analysis}

Statistical analyzes were made by GraphPad Prism 6 program (GraphPad Software, Inc. 2003). Correlations be- tween data were performed by the coefficient of Person with chart on Gaussian distribution and linear regression. In all cases, it was considered significant in all situations where the level of significance is less than $5 \%(p<0.05)$.

\section{Results}

In our study were collected blood sample of 23 patients with CKD who underwent regular hemodialysis sessions in a hospital of the city of Maceió, Brazil. Serum markers were analyzed to assess renal function such as creatinine, urea and albumin and serum dosages of triglycerides (TG), total cholesterol (TC), high density lipoprotein (HDL), low density lipoprotein (LDL) and very low density (VLDL), addition of glucose, calcium and Creactive protein. According to Table 1 , the body mass index data (BMI) and biochemistry data were within what is recommended by the world health organization, except for creatinine and urea levels, demonstrating the fact that these patients in our study has significant loss of function renal. The TG levels, TC, LDL and VLDL are within the normal range, but HDL levels (37.86 \pm 12.75$)$ are below the value recommended by National Cholesterol Education Program (NCEP) and Adult Treatment

Table 1: Metabolic profile of CKD patients.

\begin{tabular}{|l|l|}
\hline Patients number & 23 \\
\hline Time of treatment (year) & $6.86 \pm 3.93$ \\
\hline BMI & $24.41 \pm 4.80$ \\
\hline Albumin $(\mathrm{g} / \mathrm{dL})$ & $3.90 \pm 0.44$ \\
\hline Urea $(\mathrm{mg} / \mathrm{dL})^{*}$ & $132.04 \pm 36.52$ \\
\hline Glucose $(\mathrm{mg} / \mathrm{dL})$ & $108.88 \pm 58.45$ \\
\hline Creatinine $(\mathrm{mg} / \mathrm{dL})^{*}$ & $8.80 \pm 2.61$ \\
\hline Total Cholesterol (mg/dL) & $159.27 \pm 43.06$ \\
\hline VLDL $(\mathrm{mg} / \mathrm{dL})$ & $23.03 \pm 11.26$ \\
\hline LDL $(\mathrm{mg} / \mathrm{dL})$ & $98.91 \pm 33.09$ \\
\hline HDL $(\mathrm{mg} / \mathrm{dL})^{*}$ & $37.85 \pm 12.75$ \\
\hline TG $(\mathrm{mg} / \mathrm{dL})$ & $108.65 \pm 48.52$ \\
\hline CRP $(\mathrm{mg} / \mathrm{dL})$ & $1.03 \pm 1.25$ \\
\hline
\end{tabular}

The values are represented as mean and standard deviation; BMI (body mass index); HDL (high density lipoprotein); LDL (low density lipoprotein); VLDL (very low-density lipoprotein); TG (triglycerides); CRP (C-reactive protein).

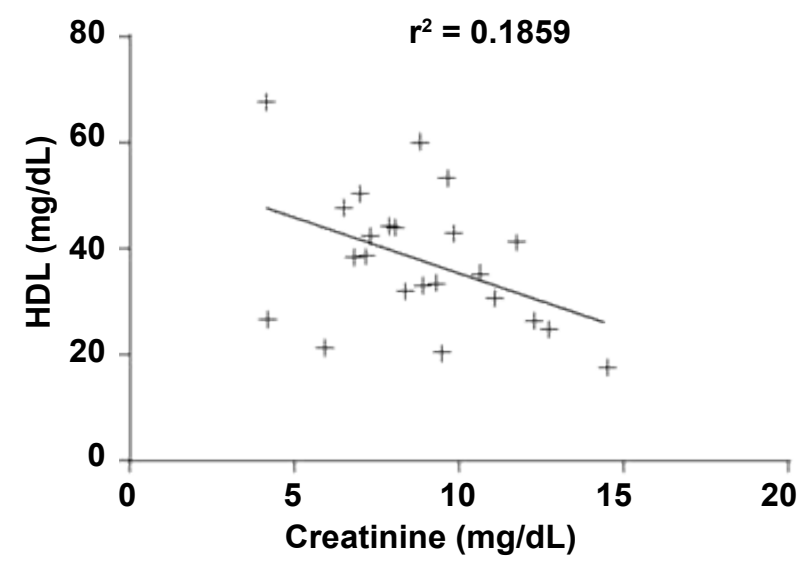

Figure 1: Negative correlation between levels of HDL (high density lipoprotein) versus creatine; Pearson correlation with linear regression; $P=0.03$. 
Panel III (ATP III) [20].

HDL levels are negatively correlated $(r=-0.431, P=$ 0.04 ) with creatinine levels (Figure 1 ). What is evidence that patients with high levels of creatinine and evidently

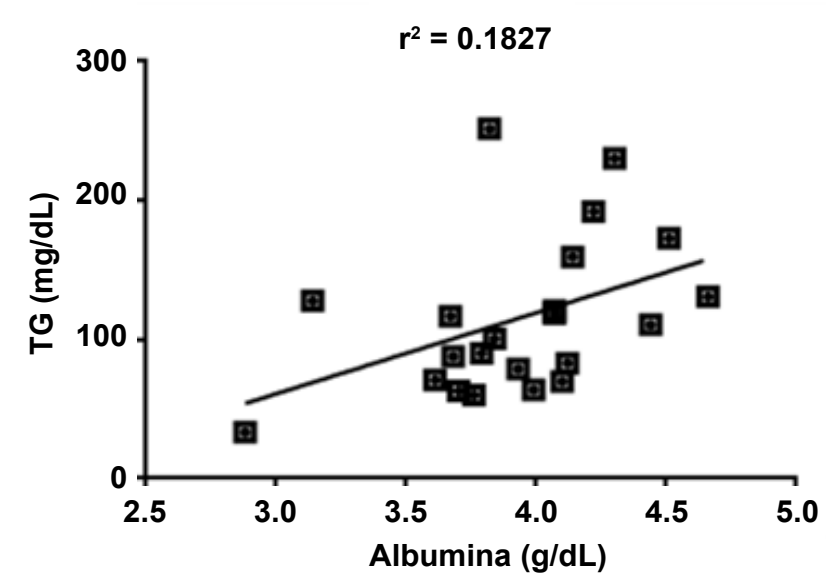

Figure 2: Positive correlation between levels of TG (triglycerides) versus albumin; Pearson correlation with linear regression; $P=0.04$.

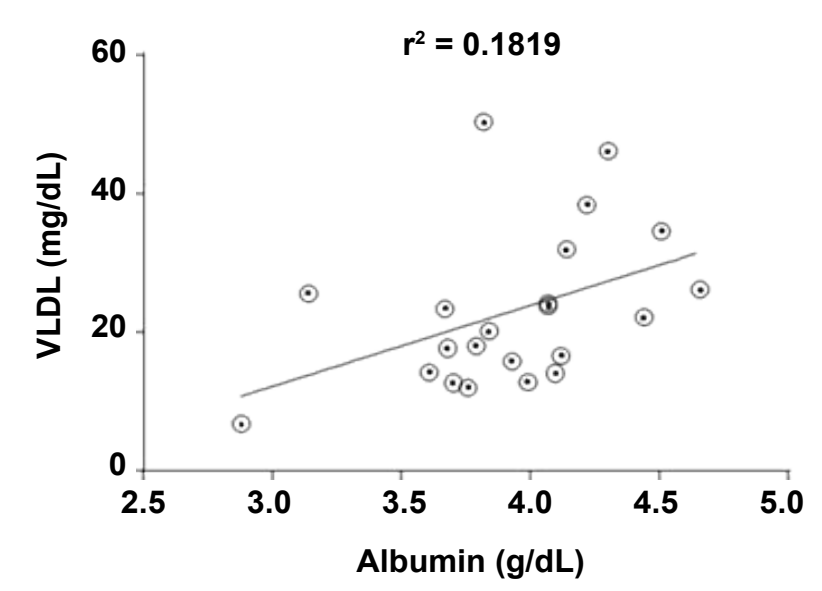

Figure 3: Positive correlation between levels of VLDL (very low density lipoprotein) versus albumin; Pearson correlation with linear regression; $P=0.04$

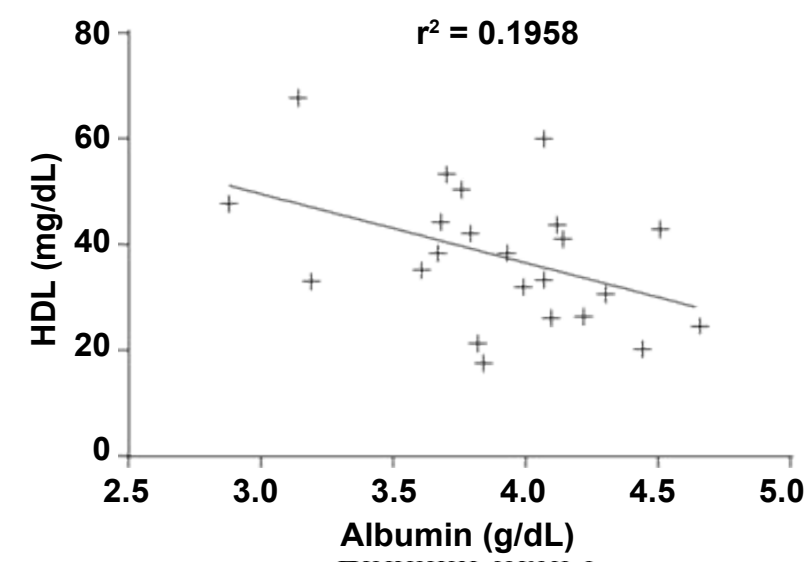

Figure 4: Positive correlation between levels of HDL (high density lipoprotein) versus albumin; Pearson correlation with linear regression; $P=0.03$. loss of renal function have a higher risk of developing atherosclerosis by lowering of HDL levels.

Despite the mean values found for serum albumin, TG, VLDL are within the recommended values, there was a positive correlation between albumin levels versus TG $(r=0.427, p=0.04)$, versus VLDL $(r=0.426 ; p=$ $0.04)$ and a negative correlation with HDL $(r=-0.422 ; p$ $=0.03$ ) (Figure 2, Figure 3 and Figure 4, respectively).

\section{Discussion}

Cardiovascular diseases are the most important and common cause of death in patients with chronic kidney disease (CKD) and dialysis processes in the US and Europe, it is estimated to account for approximately $40 \%$ and $36 \%$ of deaths in patients. They are on dialysis in the United States and Europe, respectively [3].

Moody, et al. [21] reported that patients with CKD have increased incidence of atherosclerosis and increased morbidity and mortality by cardiovascular disease. Traditional risk factors such as dyslipidemia and hypertension are present in the DRC, contributing to atherosclerosis. In addition, non-traditional risk factors such as inflammation, oxidative stress, accumulation of uremic toxins and formation of advanced glycation end products (AGE) seem to exacerbate cardiovascular risk, increased 30 -fold in patients with CKD, compared to general population [22-24].

HDL has an important antiatherogenic role because beyond its antioxidant potential, it performs the reverse cholesterol transport (RTC) [25], which is characterized by removal cholesterol from peripheral cell including macrophages and endothelial cells in the artery wall by HDL particles or their precursors and transport cholesterol to the liver for being eliminated in the bile and excreted in the faeces.

In our study, besides having shown that HDL levels are already reduced in patients with CKD, we found that when the worse the renal status of that patient, assessed by measuring creatinine, lower the HDL levels in these individuals (Figure 1).

Several studies have demonstrated changes in the RTC in experimental uremia, and in patients with DRC $[26,27]$, resulting largely by increased serum cholesterol and triglycerides, which in turn favor the enrichment of atherogenic lipoproteins, such as LDL and Lp (a) $[22,28,29]$.

Lipoprotein (a) or Lp (a) is associated with increased prevalence of cardiovascular disease, primarily by inducing hemostatic disturbances (competition with plasminogen) and proliferation of smooth muscle cells. This lipoprotein presents itself elevated in patients with CKD and its increase correlates negatively with glomerular filtration rate $[30,31]$.

In our study did not evaluate the concentration of 
$L p(a)$, but the average levels of triglycerides (TG), cholesterol, VLDL and LDL there was no change in CRF patients. However, we observe that there is positive correlation with serum albumin levels with the levels of TG, and VLDL (Figure 2 and Figure 3 ) and a negative correlation with HDL (Figure 4).

Serum albumin has been identified as an important nutritional marker of chronic kidney disease [32]. Morsch, et al. [33] show that when smaller the higher albumin levels are the severity index of kidney disease. Lowrie, et al. [34] reported there is an increased risk of mortality in patients undergoing hemodialysis or peritoneal dialysis when the serum albumin levels are less than $2.5 \mathrm{~g} / \mathrm{dL}$.

Serum albumin values in our study are within the recommended values (Table 1 ), demonstrating that patients in the study found to be eutrophic in relation to nutritional status.

Most of the above studies show that dyslipidemia is an important factor for the onset of cardiovascular disease in patients with CKD. Although not been an increase in the amount of TG, VLDL, LDL and TC (Table 1), there is a positive correlation between the albumin and to TG, and VLDL, followed by a decreased in HDL levels.

Vaziri, et al. [26] demonstrated that the lowest concentration of HDL derives from the decrease in the metabolism of triglyceride-rich lipoproteins, although the reduction in the rate of synthesis of apo Al and A-II by the liver and the increase in the activity of cholesteryl ester transfer protein (CETP) also contribute to a decrease in plasma.

It is known that the hypoalbuminemia is an important marker of morbidity and mortality in CKD patients, however, so far there is no evidence that the correction of serum albumin can improve the survival of patients in hemodialysis [32]. Moreover, in patients with CKD there is an increase in the formation of uremic toxins, as well as advanced glycation end products that contribute to cellular oxidative stress and modifying LDL or even plasma proteins such as albumin, making them more susceptible to the type receptors "scavenger" in arterial macrophages, contribute to the development of atherosclerosis in these individuals.

More detailed studies on the profile of CKD patient's lipoproteins should be conducted to functionally evaluate the power anti-atherogenic or pro-atherogenic of these lipoproteins.

\section{Conclusion}

In our study we demonstrated that in patients with chronic kidney disease there is an increased risk of developing atherosclerosis. This increase in the risk of developing atherosclerosis and cardiovascular disease is not due to the increase of blood cholesterol or triglycerides, but by a decreased level of HDL.
We also observed that there is a correlation between creatinine levels to HDL levels, demonstrating that when the worse the condition of the renal functionality, the lower the HDL level and this is the main factor that contributes to cellular cholesterol accumulation and consequently favoring the genesis and development of atherosclerosis in these patients.

\section{References}

1. Dummer CD, Thomé FS, Veronese FV (2007) Chronic renal disease, inflammation and atherosclerosis: New concepts about an old problem. Rev Assoc Med Bras 53: 446-450.

2. Foley RN, Prafrey PS, Sarnak MJ (1998) Clinical epidemiology of cardiovascular disease in chronic renal disease. Am J Kidney Dis 32: S112-S119.

3. Shlipak MG, Fried LF, Cushman M, Manolio TA, Peterson $\mathrm{D}$, et al. (2005) Cardiovascular mortality risk in chronic kidney disease: Comparison of traditional and novel risk factors. JAMA 293: 1737-1745.

4. Vaziri ND (2004) Oxidative stress in uremia: Nature, mechanism, and potencial consequences. Semin Nephrol 24: 469-473.

5. Myata T, Kurokawa K, Van Ypersie De Strihou C (2000) Relevance of oxidative and carbonyl stress to long-term uremic complications. Kidney Int Suppl 76: S120-S125.

6. Drueke TB, Nguyen Khoa T, Massy ZA, Witko-Sarsat V, Lacour B, et al. (2001) Role of oxidized low-density lipoprotein in the atherosclerosis of uremia. Kidney Int Suppl 78: S114-S119.

7. Zhang Z, Dmitrieva NI, Park JH, Levine RL, Burg MB (2004) High urea and $\mathrm{NaCl}$ carbonylate proteins in renal cell in culture and in vivo, and high urea causes 8-oxoguanine lesions in their DNA. Proc Natl Acad Sci U S A 101: 9177-9178.

8. D'apolito M, Du X, Zong H, Catucci A, Maiuri L, et al. (2010) Urea-induced ROS generation causes insulin resistance in mice with chronic renal failure. J Clin Invest 120: 203-213.

9. Myata T, Sugiyama S, Saito A, Kurokawa K (2001) Reactive carbonyl compounds related uremic toxicity ("carbonyl stress"). Kidney Int Suppl 78: S25-S31.

10. Corrêa-Camacho CR, Dias-Melicio LA, Soares AMVC (2007) Aterosclerose, uma resposta inflamatória. ArqCiên Saúde 14: 41-48.

11. Martins IS, Marucci MFN, Cervato AM, Okami ET, Mazzili RN, et al. (1996) Doenças cardiovasculares ateroscleróticas, dislipidemias, hipertensão, obesidade e diabetes mellitus em população da área metropolitania da região Sudeste do Brasil: II-Deslipidemias. Rev. Saúde Pública 30: 75-84.

12. Penalva RA, Huoya MO, Correia LCL, Feitosa GS, Ladeia AMT (2008) Perfil lipídico e da gravidade da doença aterosclerótica em síndrome coronária aguda. Arq Bras Cardiol 90: 1.

13. Joles JA, Stroes ES, Rabelink TJ (1999) Endothelial function in proteinuric renal disease. Kidney Int Suppl 71: S57-S61.

14. Quaschning T, Krane V, Metzger T, Wanner C (2001) Abnormalities in uremic lipoprotein metabolism and its impact on cardiovascular disease. Am J Kidney Dis 38: S14-S19.

15. Attman PO, Samuelsson O, Alaupovic P (1993) Lipoprotein metabolism and renal failure. Am J Kidney Dis 21: 573-592. 
16. Massy ZA, Mamzer-Bruneel MF, Chevalier A, Millet $P$, Helenon O, et al. (1998) Carotid atherosclerosis in renal transplant recipients. Nephrol Dial Transplant 13: 17921798.

17. Wanner C, Quaschning T (2001) Dyslipidemia and renal disease: Pathogenesis and clinical consequences. Curr Opin Nephrol Hypertens 10: 195-201.

18. Trevisan R, Dodesini AR, Lepore G (2006) Lipids and renal disease. J Am Soc Nephrol 17: S145-S147.

19. Bairaktari E, Hatzidimou K, Tzallas C, Vini M, Katsaraki $A$, et al. (2000) Estimation of LDL cholesterol based on the Friedewald formula and on apo B levels. Clin Biochem 33: 549-555.

20. Expert Panel on Detection, Evaluation, and Treatment of High Blood Cholesterol in Adults (2001) Executive summary of the third report of the National Cholesterol Education Program (NCEP) expert panel on detection, evaluation, and treatment of high blood cholesterol in adults (Adult Treatment Panel III). JAMA 285: 2486-2497.

21. Moody WE, Edwards NC, Chue CD, Ferro CJ, Townend JN (2013) Arterial disease in chronic kidney disease. Heart 99: 365-372.

22. Moradi H, Pahl MV, Elahimehr R, Vaziri ND (2009) Impaired antioxidant activity of high-density lipoprotein in chronic kidney disease. Transl Res 153: 77-85.

23. Apostolov EO, Ray D, Savenka AV, Shah SV, Basnakian AG (2010) Chronic Uremia Stimulates LDL carbamylation and atherosclerosis. J Am Soc Nephrol 21: 1852-1857.

24. Hörl WH, Cohen JJ, Harrington JT, Madias NE, Zusman CJ (2004) Atherosclerosis and uremic retention solutes. Kidney Int 66: 1719-1731.

25. Quintão EC, Medina WL, Passarelli M (2000) Reverse cholesterol transport in diabetes mellitus. Diabetes Metab Res Ver 16: 237-250.
26. Vaziri ND (2010) Lipotoxicity and impaired high-density lipoprotein-mediated reverse cholesterol transport in chronic kidney disease. J Ren Nutr 20: S35-S43.

27. Glodny B, Nasseri P, Rehder P, Unterholzner V, Plaikner $M$, et al. (2011) Reduced glomerular filtration rate due to loss of nephron mass may be an independent risk factor for atherosclerosis. Nephrol Dial Transplant 26: 1882-1887.

28. Attman PO, Samuelsson O, Johansson AC, Moberly JB, Alaupovic P (2003) Dialysis modalities and dyslipidemia. Kidney Int Suppl 84: S110-S112.

29. Deighan CJ, Caslake MJ, Mcconnell M, Boulton-Jones JM, Packard CJ (2000) Atherogenic lipoprotein phenotype in end-stage renal failure: Origin and extent of small dense low-density lipoprotein formation. Am J Kidney Dis 35: 852862.

30. Longenecker JC, Klag MJ, Marcovina SM, Liu YM, Jaar BG, et al. (2005) High lipoprotein(a) levels and small apolipoprotein(a) size prospectively predict cardiovascular events in dialysis patients. J Am Soc Nephrol 16: 1794-1802.

31. Rao AM, Bitla AR, Reddy EP, Sivakumar V, Srinivasa Rao PV (2010) Lipid abnormalities, lipoprotein (a) and apoprotein pattern in non-dialyzed patients with chronic kidney disease. Indian J Clin Biochem 25: 47-50.

32. Santos NSJ, Draibe SA, Kamimura MA, Cuppari L (2004) Albumina sérica como marcador nutricional de pacientes de hemodiálises. Rev Nutr 17: 339-349.

33. Morsch C, Gonçalves LF, Barros E (2005) Índice de gravidade da doença renal, indicadores assistenciais e mortalidade em pacientes em hemodiálise. Rev Assoc Med Bras 51: 296-300.

34. Lowrie EG, Huang WH, Lew NL (1995) Death risk predictors among peritoneal dialysis e hemodialysis patients: A preliminary comparison. Am J Kidney Dis 26: 220-228. 